\title{
Artigo/Article
}

\section{Arraias em rios da região Sudeste do Brasil: locais de ocorrência e impactos sobre a população}

\author{
Stingrays in rivers in southeastern Brazil: occurrence localities and impact on the \\ population
}

\section{Domingos Garrone Neto ${ }^{1}$ Vidal Haddad Junior ${ }^{2}$}

\begin{abstract}
RESUMO
Introdução: No presente trabalho objetivamos descrever o processo de colonização da Bacia do Alto Paraná, Sudeste do Brasil, por arraias, demonstrando sua atual situação e provável tendência, os impactos gerados e discutindo algumas ações de manejo e medidas mitigadoras. Métodos: Foram realizadas entrevistas com ribeirinhos e profissionais de saúde para o levantamento de informações sobre a ocorrência de arraias e acidentes associados a estes animais, além de coletas e observações subaquáticas de potamotrigonídeos, entre 2004 e 2009, em localidades situadas nos Estados de São Paulo, Paraná e Mato Grosso do Sul, no Sudeste, Sul e parte do Centro-Oeste do Brasil. Resultados: Três espécies de arraias foram identificadas na área de estudo, demonstrando utilizar os caminhos abertos pela Hidrovia Tietê-Paraná para se dispersarem. Dezesseis vítimas de acidentes envolvendo esses animais foram encontradas, notadamente banhistas e pescadores, chamando a atenção pelo fato dos casos não serem notificados e apresentarem elevada morbidade, com marcante incapacidade temporária para o trabalho. Conclusões: Este é o primeiro relato de invasão biológica envolvendo espécies de elasmobrânquios conhecido na literatura e, pelas arraias estarem colonizando áreas densamente povoadas e ampliando sua área de distribuição a cada ano, é de se esperar que sua interação negativa com humanos se intensifique, provocando alterações importantes no perfil epidemiológico dos acidentes por animais peçonhentos ocorridos no sudeste brasileiro.
\end{abstract}

Palavras-chaves: Animais peçonhentos. Epidemiologia. Arraias fluviais. Potamotrygonidae.

\begin{abstract}
Introduction: In this paper, our aim was to describe the process of colonization of the upper Paraná basin, southeastern Brazil, by stingrays, showing the current situation, likely trend and impact caused and discussing some management actions and mitigation measures. Methods: Interviews were held with riverbank people and health professionals, to gather information on occurrences of stingrays and accidents associated with these animals, along with underwater observations and collection of specimens, between 2004 and 2009 in localities in the States of São Paulo, Paraná and Mato Grosso do Sul, in the southeastern, southern and part of the central-western regions of Brazil. Results: Three species of stingrays were identified in the study area, thus demonstrating that they were using the paths opened by the Tietê-Paraná Waterway to disperse. Sixteen victims of accidents involving these animals were found, mainly bathers and fishermen. Attention was drawn to the fact that these cases had not been reported, yet they presented high morbidity with notable temporary incapacity for work. Conclusions: This is the first report on biological invasion involving species of elasmobranchs in the literature and, because stingrays are colonizing densely populated areas and are expanding their range of distribution each year, it can be expected that their negative interactions with humans will intensify, with important changes in the epidemiological profile of accidents due to venomous animals occurring in southeastern Brazil.
\end{abstract}

Key-words: Venomous animals. Epidemiology. Freshwater stingrays. Potamotrygonidae.

1. Pró-Reitoria de Pesquisa e Pós-Graduação, Universidade do Sagrado Coração, Bauru, SP. 2. Departamento de Dermatologia e Radioterapia, Faculdade de Medicina, Universidade Estadual Paulista, Botucatu, SP.

Endereço para correspondência: Dr. Domingos Garrone Neto. PRPPG/USC. Rua Irmã Arminda 10-50, 17011-160 Bauru, SP.

Tel: $55143208-0696$

e-mail: garroneneto@yahoo.com

Recebido para publicação em 03/07/2009

Aceito em 08/01/2010

\section{INTRODUÇÃO}

Arraias (ou raias) de água doce pertencem à Família Potamotrygonidae e possuem ocorrência restrita aos principais sistemas fluviais da América do $\mathrm{Sul}^{1}$. O grupo apresenta histórico taxonômico problemático e a atual distribuição das cerca de vinte espécies inclui rios de diversos países sul-americanos, sobretudo do Brasil, onde os potamotrigonídeos, além de serem procurados por aquariofilistas e eventualmente utilizados como recurso alimentar, são conhecidos por poderem provocar ferimentos muito dolorosos em humanos ${ }^{2,3}$.

No Estado de São Paulo e nos municípios paranaenses e sul-matrogossenses localizados às margens do Rio Paraná, à montante das Sete-Quedas de Guaíra/PR, arraias não faziam parte da fauna aquática nativa até o final da década de $1970^{4}$. No entanto, com o fim do enchimento do reservatório da Usina Hidrelétrica de Itaipu em 1982, a importante barreira geográfica representada pelas Sete-Quedas foi submersa, possibilitando a colonização do trecho situado à montante de Guaíra por estes animais, que vem se aproveitando dos canais artificiais e das eclusas instaladas nas barragens para o funcionamento da Hidrovia Tietê-Paraná para ampliar sua área de distribuição, despertando interesse pelos impactos gerados sobre a população ribeirinha e turistas ${ }^{5,6}$.

Considerando que arraias fluviais são animais dotados de toxinas e que sua interação com humanos pode se dar de forma negativa, a realização de pesquisas na área é relevante. Levando-se em conta, ainda, que o Rio Paraná e seus principais tributários foram modificados pela ação do homem, o que provocou sérias alterações na composição original da fauna, informações sobre o papel desempenhado por espécies exóticas, especialmente aquelas que podem oferecer riscos à população, são importantes para a administração destes ecossistemas.

Nesse contexto, o presente trabalho objetivou salientar a necessidade do conhecimento do processo 
de colonização de rios da região Sudeste do Brasil por arraias, indicando sua atual situação e provável tendência, demonstrando os impactos gerados pela chegada desses animais na região mais populosa do país e discutindo algumas ações de manejo e medidas mitigadoras. Como complemento, foram inseridas informações sobre os procedimentos terapêuticos a serem adotados no atendimento às vítimas de acidentes por arraias, com base nos resultados de pesquisas clínicas e experimentais.

\section{MÉTODOS}

Para a coleta dos dados utilizados neste estudo, realizamos entrevistas, coletas de material e observações subaquáticas entre 2004 e 2009, em localidades dos Estados de São Paulo, Paraná e Mato Grosso do Sul, no Sudeste, Sul e parte do Centro-Oeste do Brasil (Figura 1).
Para as entrevistas, utilizamos dois tipos de questionários. $\mathrm{O}$ primeiro foi empregado em um estudo de morbidade referida, junto a vítimas de acidentes por arraias sofridos nas áreas situadas à montante das Sete-Quedas de Guaíra. Para isso, realizou-se a procura ativa dos casos, após consultas a associações de pescadores, unidades de saúde, farmácias, representantes da medicina popular (raizeiros), entre outros, pesquisando-se as seguintes variáveis: características do acidentado, local, data aproximada e circunstâncias em que o acidente ocorreu, primeiros socorros empregados para o manejo do acidentado, se houve ou não a procura por atendimento médico e como o caso evoluiu. $\mathrm{O}$ segundo questionário foi direcionado aos profissionais de saúde (médicos e enfermeiros), com o objetivo de avaliar seu conhecimento sobre a ocorrência de arraias na região do Alto Rio Paraná, as ações de suas toxinas e a conduta médica a ser adotada em casos de acidentes envolvendo esses animais.

Para o conhecimento sobre a atual distribuição geográfica e a diversidade das espécies de arraias que ocorrem nas áreas que estão

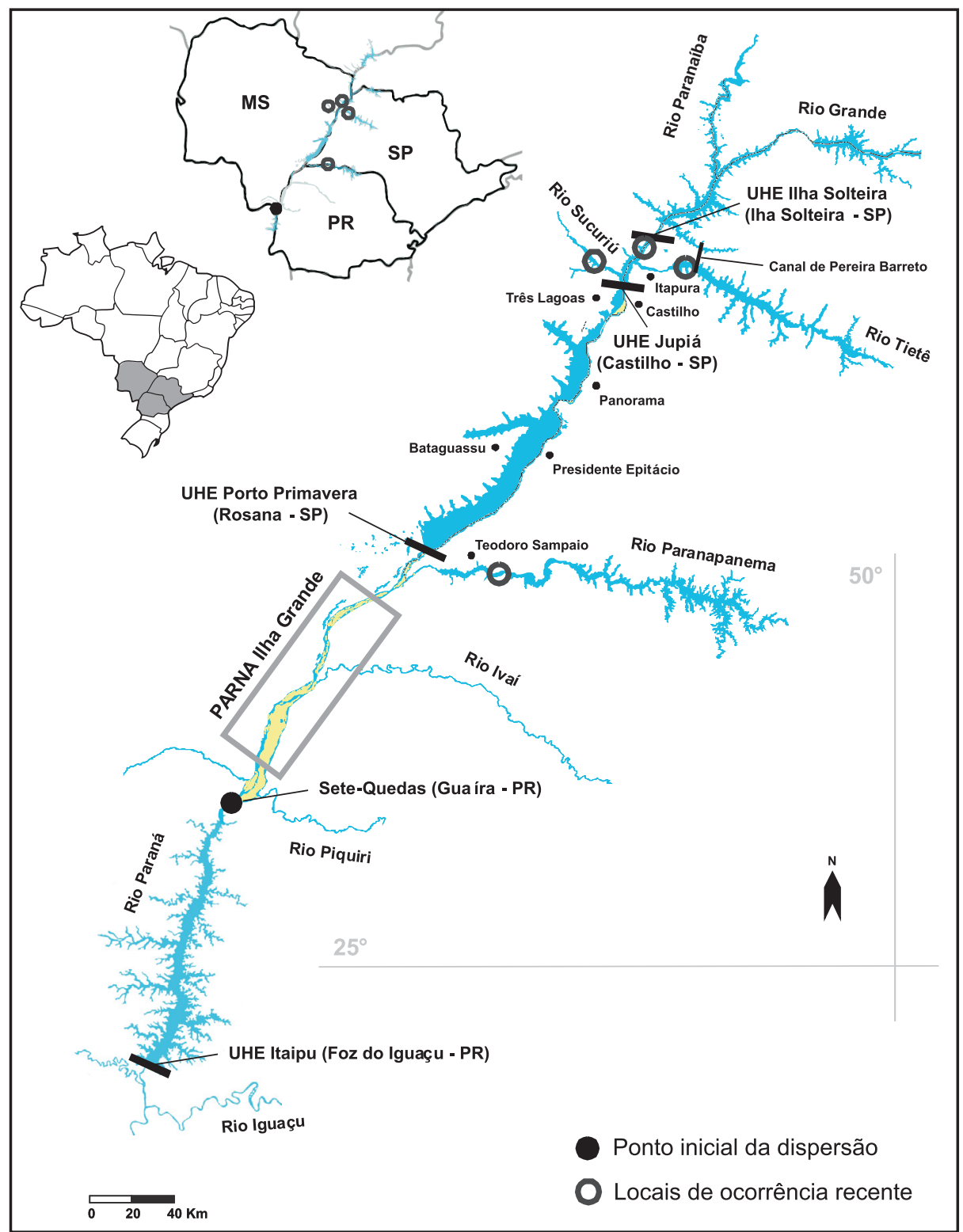

FIGURA 1 - Região do Alto Rio Paraná, Sudeste do Brasil. São demonstrados o ponto inicial de dispersão das espécies de arraias na bacia e seus locais de ocorrência recente, além dos principais rios da área de estudo e usinas hidrelétricas e eclusas instaladas ao longo de seus cursos. São também apontados os municípios onde as entrevistas, coletas de material biológico e observações subaquáticas foram realizadas. 
sendo colonizadas, coletas e observações subaquáticas desses animais foram realizadas na região do Parque Nacional de Ilha Grande (PARNA Ilha Grande) (Guaíra/PR), no Campinal (Panorama/ SP), na área da Usina Hidrelétrica Engenheiro Souza Dias (UHE Jupiá) (Castilho/SP) e em Ilha Solteira/SP, e nos baixos cursos dos rios Paranapanema (Rosana e Teodoro Sampaio/SP), Sucuriú (Três Lagoas/MS) e Tietê (Itapura e Pereira Barreto/SP). Espécimestestemunho foram depositados nas coleções do Museu de Zoologia "Prof. Dr. Adão José Cardoso" da Universidade Estadual de Campinas (Campinas/SP) e do Laboratório de Ecologia e Sistemática da Universidade Federal da Paraíba (João Pessoa/PB), onde estão disponíveis para consulta.

\section{RESULTADOS}

Embora tenhamos conhecimento de pelo menos 31 relatos sobre acidentes por arraias ocorridos na região do Alto Rio Paraná, em nenhuma unidade de saúde visitada encontramos registros desse tipo de agravo. A procura ativa por casos foi a única forma de levantar informações a esse respeito, resultando no encontro de 16 vítimas (Tabela 1), boa parte procedente do Estado de São Paulo $(n=10)$. Apenas uma era do sexo feminino. Com exceção de nove casos recentes (quatro em 2009, um em 2008, dois em 2007 e dois em 2006), os demais ocorreram a mais de cinco anos, tendo o caso mais antigo registrado por nós ocorrido em um pescador profissional de Presidente Epitácio/SP no ano de 1993.

As vítimas foram banhistas ( $\left.\mathrm{n}^{\mathrm{o}}=9\right)$, pescadores profissionais $\left(\mathrm{n}^{\mathrm{o}}=3\right)$, pescadores amadores $\left(\mathrm{n}^{\mathrm{o}}=3\right)$ e um pesquisador. A idade média das vítimas foi de 24 anos (13 a 46 anos). Quatro vítimas não residiam no ou próximo do local do acidente. As regiões anatômicas mais acometidas foram os membros inferiores em banhistas $\left(\mathrm{n}^{\mathrm{o}}=8\right)$ e os superiores em pescadores e no pesquisador $\left(\mathrm{n}^{\mathrm{o}}=5\right)$. Acidentes envolvendo banhistas ocorreram apenas durante o período diurno, especialmente à tarde $\left(\mathrm{n}^{\mathrm{o}}=6\right)$, quando estes se refrescavam com a água na altura da cintura/peito $(\mathrm{n}=8)$ ou nadavam/mergulhavam $(\mathrm{n}=1)$, em locais com substrato predominantemente arenoso. Os casos ocorridos em pescadores que tiveram os membros inferiores acometidos $\left(\mathrm{n}^{\mathrm{o}}=2\right)$ ocorreram em circunstâncias semelhantes às relatadas pela maioria dos banhistas, durante o dia ou à noite, quando da procura por locais favoráveis à pesca, sem o uso de embarcações.

Tanto nos banhistas quanto nos pescadores com acometimento de membros inferiores, os acidentes se concentraram nos meses mais quentes e chuvosos da região Sudeste do Brasil (novembro a março) e as vítimas relataram ter sentido um golpe violento, repentino, no tornozelo $\left(\mathrm{n}^{\mathrm{o}}=5\right)$ ou pé $\left(\mathrm{n}^{\mathrm{o}}=5\right)$. Já o acidente com o pesquisador e os casos envolvendo pescadores, que tiveram os membros superiores atingidos pelas ferroadas $(\mathrm{n}=3)$, ocorreram durante a manipulação de arraias capturadas em anzóis ou redes, sem sazonalidade marcante, predominantemente no período noturno, dentro de embarcações.

A dor foi o principal sintoma relatado em todos os casos, surgindo imediatamente após a ferroada, com grande intensidade, acompanhada do aparecimento de edema e eritema locais. Com exceção do caso envolvendo o pesquisador, em todos os casos se estabeleceu necrose cutânea de gravidade variável após cerca de sete dias (Figura 2). Sintomas sistêmicos foram relatados em seis das 16 vítimas, que referiram taquicardia, febre, sudorese fria, náuseas, vômitos e agitação. Dentre os primeiros-socorros empregados pelas
TABELA 1- Características principais dos acidentes por arraias observados na região do Alto Rio Paraná, Sudeste do Brasil. 2004-2009.

\begin{tabular}{|c|c|c|}
\hline \multirow[b]{2}{*}{ Variáveis } & \multicolumn{2}{|c|}{ População estudada } \\
\hline & $\mathrm{n}^{\mathrm{o}}$ & $\%(\sim)$ \\
\hline \multicolumn{3}{|l|}{ Sexo acometido } \\
\hline masculino & 15 & 94,0 \\
\hline feminino & 1 & 6,0 \\
\hline \multicolumn{3}{|l|}{ Idade da vítima (anos) } \\
\hline$<15$ & 4 & 25,0 \\
\hline 16 a 30 & 10 & 62,5 \\
\hline$>30$ & 2 & 12,5 \\
\hline \multicolumn{3}{|l|}{ Categoria } \\
\hline banhista & 9 & 56,0 \\
\hline pescador amador/esportivo & 3 & 19,0 \\
\hline pescador profissional & 3 & 19,0 \\
\hline pesquisador & 1 & 6,0 \\
\hline \multicolumn{3}{|l|}{ Região anatômica atingida } \\
\hline membros superiores & 5 & 31,0 \\
\hline membros inferiores & 10 & 62,5 \\
\hline outros (tronco) & 1 & 6,5 \\
\hline \multicolumn{3}{|l|}{ Período do dia } \\
\hline manhã & 4 & 25,0 \\
\hline tarde & 8 & 50,0 \\
\hline noite & 4 & 25,0 \\
\hline \multicolumn{3}{|l|}{ Atividade no momento do acidente } \\
\hline caminhando dentro d'água & 10 & 63,0 \\
\hline retirando arraia de anzol/rede & 4 & 25,0 \\
\hline manipulando/transportando arraia & 1 & 6,0 \\
\hline nadando/mergulhando & 1 & 6,0 \\
\hline \multicolumn{3}{|l|}{ Principais sintomas } \\
\hline dor & $16 / 16$ & 100,0 \\
\hline edema & $16 / 16$ & 100,0 \\
\hline necrose cutânea & $15 / 16$ & 94,0 \\
\hline \multicolumn{3}{|l|}{ Procura por atendimento médico } \\
\hline $\operatorname{sim}$ & 10 & 62,5 \\
\hline não & 6 & 37,5 \\
\hline \multicolumn{3}{|l|}{ Notificação do caso } \\
\hline $\operatorname{sim}$ & 0 & 0,00 \\
\hline não & 16 & 100,0 \\
\hline Total & 16 & 100,0 \\
\hline
\end{tabular}

vítimas, a limpeza dos ferimentos com água de rio/lagoa foi relatada em todos os casos, combinada com o uso de água ardente $\left(\mathrm{n}^{\circ}=8\right)$, álcool de cozinha $\left(\mathrm{n}^{\mathrm{o}}=7\right)$, urina $\left(\mathrm{n}^{\circ}=4\right)$, fumo e borra de café $\left(\mathrm{n}^{\mathrm{o}}=4\right)$ e gasolina $\left(\mathrm{n}^{\mathrm{o}}=3\right)$ sobre o ferimento ou seguida da imersão do membro atingido em água quente não escaldante $\left(\mathrm{n}^{\mathrm{o}}=2\right)$. A procura por atendimento médico foi realizada por dez vítimas, logo em seguida $\left(\mathrm{n}^{\mathrm{o}}=4\right)$ ou em até dois dias depois do acidente $\left(\mathrm{n}^{\mathrm{o}}=6\right)$. Os quadros agudos (até cerca de 24 horas) foram extremamente incapacitantes, sobretudo aqueles com acometimento de membros inferiores. $\mathrm{O}$ tempo médio de cicatrização das úlceras foi de três meses. Infecções secundárias, observadas por nós no campo ou relatadas pelas vítimas devido à presença de secreção purulenta no ferimento e fenômenos sistêmicos como febre, foram relatadas em treze casos, mas não foi possível identificar as bactérias envolvidas. Não houve nenhum caso fatal e o quadro clínico das vítimas evoluiu para cura sem sequelas, deixando grandes cicatrizes nas áreas comprometidas em 15 casos. 


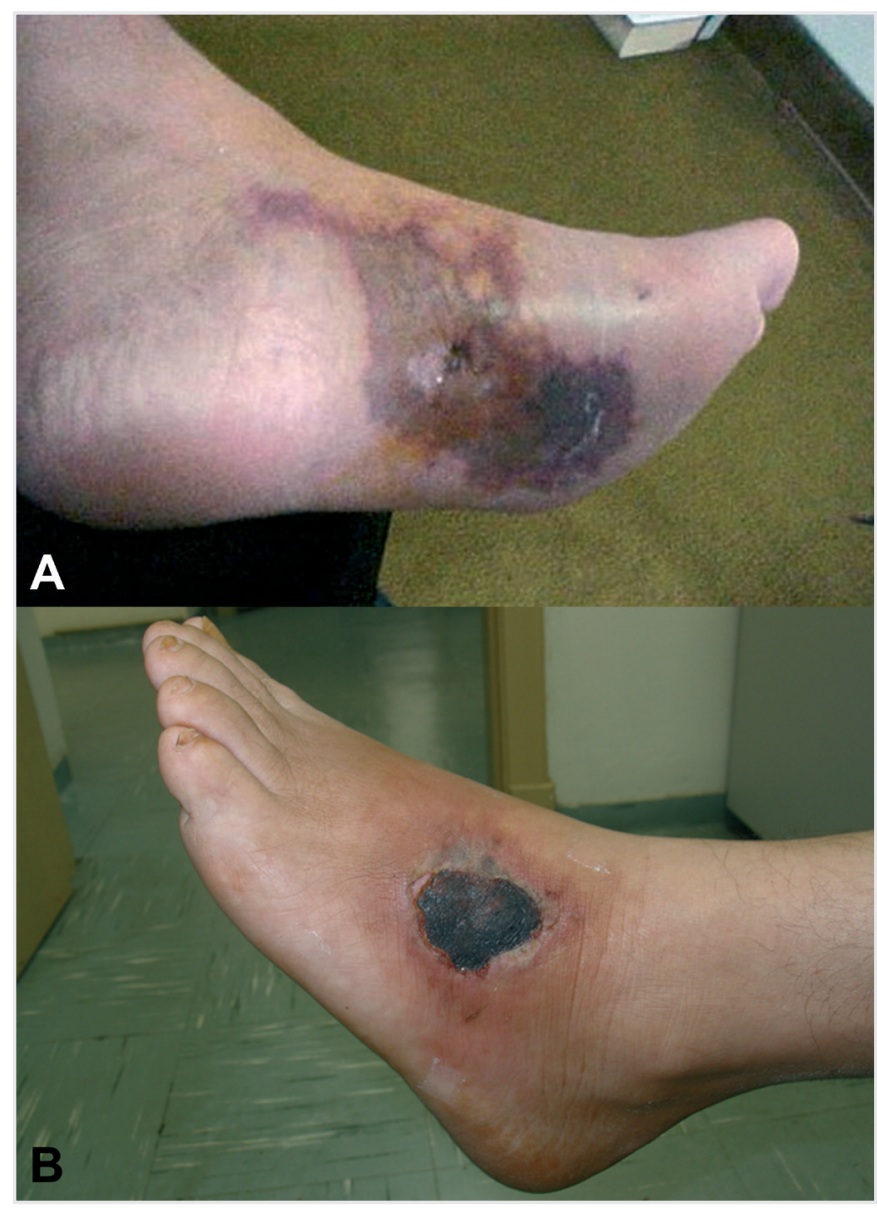

FIGURA 2 - A) Acidentes observados em vítimas procedentes da região de Presidente Epitácio, SP. Necrose superficial instalada ao redor do local da ferroada 48 horas após o acidente. B) Escara enegrecida, resultante do tecido necrosado pela ação das toxinas, em acidente com cerca de oito dias de evolução.
Sete médicos e 12 enfermeiros inseridos a mais de cinco anos no serviço de saúde de municípios situados na área de estudo foram entrevistados. Destes, apenas quatro relataram estar cientes da colonização da região do Alto Rio Paraná por arraias. A maioria, por não ser oriunda da região, desconhecia sua ocorrência na bacia, a presença de toxinas nesses animais e até mesmo a existência de espécies de arraias de água doce no Brasil. Para todos, embora tenham referido nunca ter atendido casos de acidentes por arraias, a limpeza dos ferimentos com antissépticos, associada à aplicação de anestesia local e administração de algum tipo de antibiótico via oral, foi apontada como a conduta de atendimento adequada às vítimas.

As coletas de material biológico e observações subaquáticas realizadas, demonstraram a ocorrência de pelo menos três espécies de arraias na região do Alto Rio Paraná: Potamotrygon falkneri, Potamotrygon motoro e Potamotrygon schuhmacheri (Figura 3). P. falkneri e P. motoro foram as espécies mais abundantes, sendo encontradas do PARNA Ilha Grande aos baixos cursos dos rios Paranapanema, Sucuriú e Tietê, além de outros tributários. P. schuhmacheri ocorreu com menor frequência, tendo sido observada apenas na região do PARNA Ilha Grande. Todas possuem de um a três ferrões de formato retrosserrilhado na cauda (Figura 4AB), desferindo ferroadas quando pisadas inadvertidamente ou manipuladas sem o devido cuidado ${ }^{2,7,8}$. A estrutura dos aguilhões é bastante rígida e o epitélio que os recobre possui toxinas, cuja composição e mecanismo de ação, apesar de ainda não serem totalmente conhecidos, incluem pelo menos 18 substâncias ${ }^{8-12}$.

Na Figura 1, demonstramos o ponto inicial de dispersão das arraias e seus novos locais de ocorrência na região do Alto Rio Paraná. São também apontados os municípios onde as entrevistas, coletas de material biológico e observações subaquáticas foram realizadas.

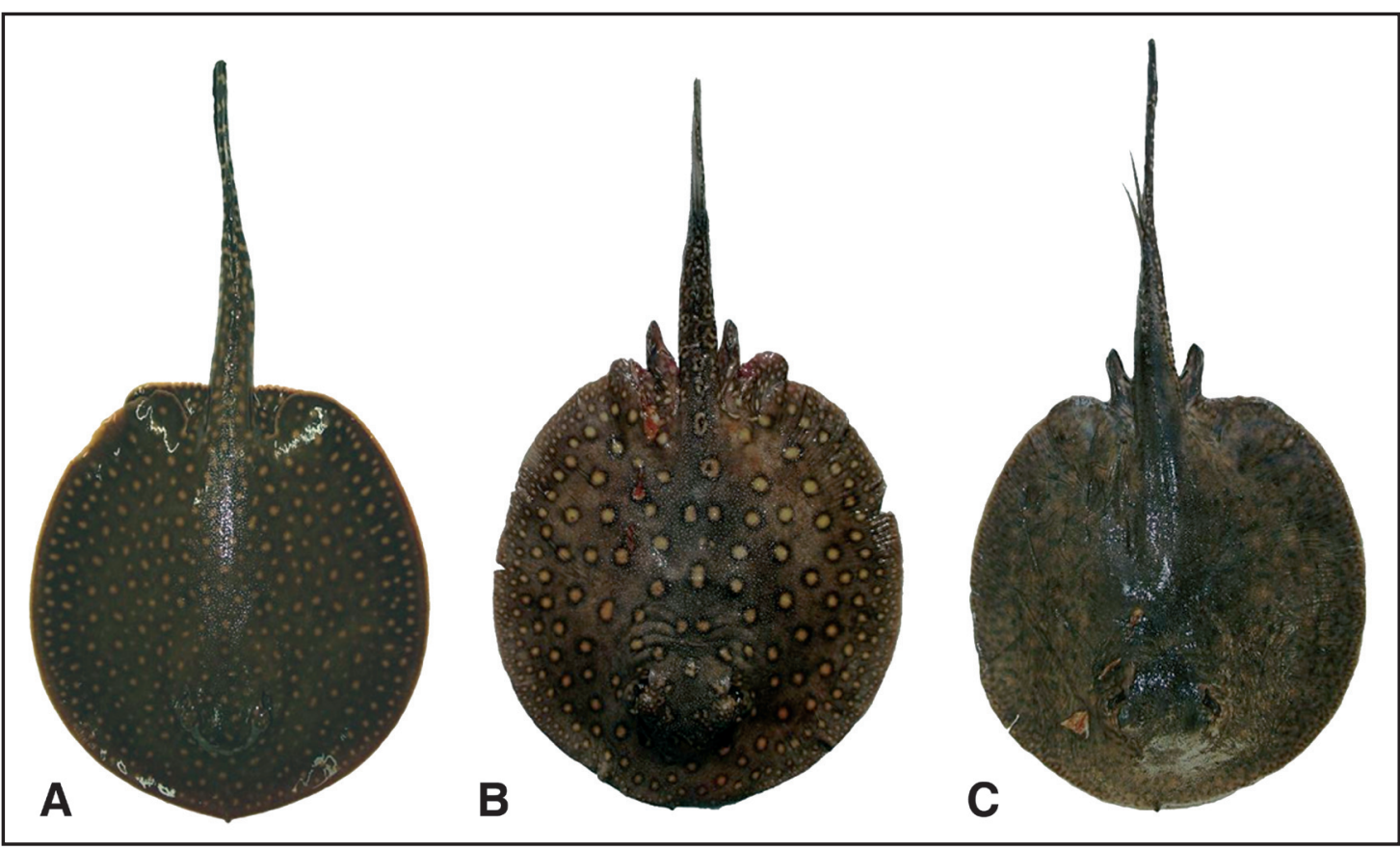

FIGURA 3 - Espécies do gênero Potamotrygon com ocorrência registrada para a região do Alto Rio Paraná: A) Potamotrygon falkneri, B) Potamotrygon motoro e C) Potamotrygon schuhmacheri. 


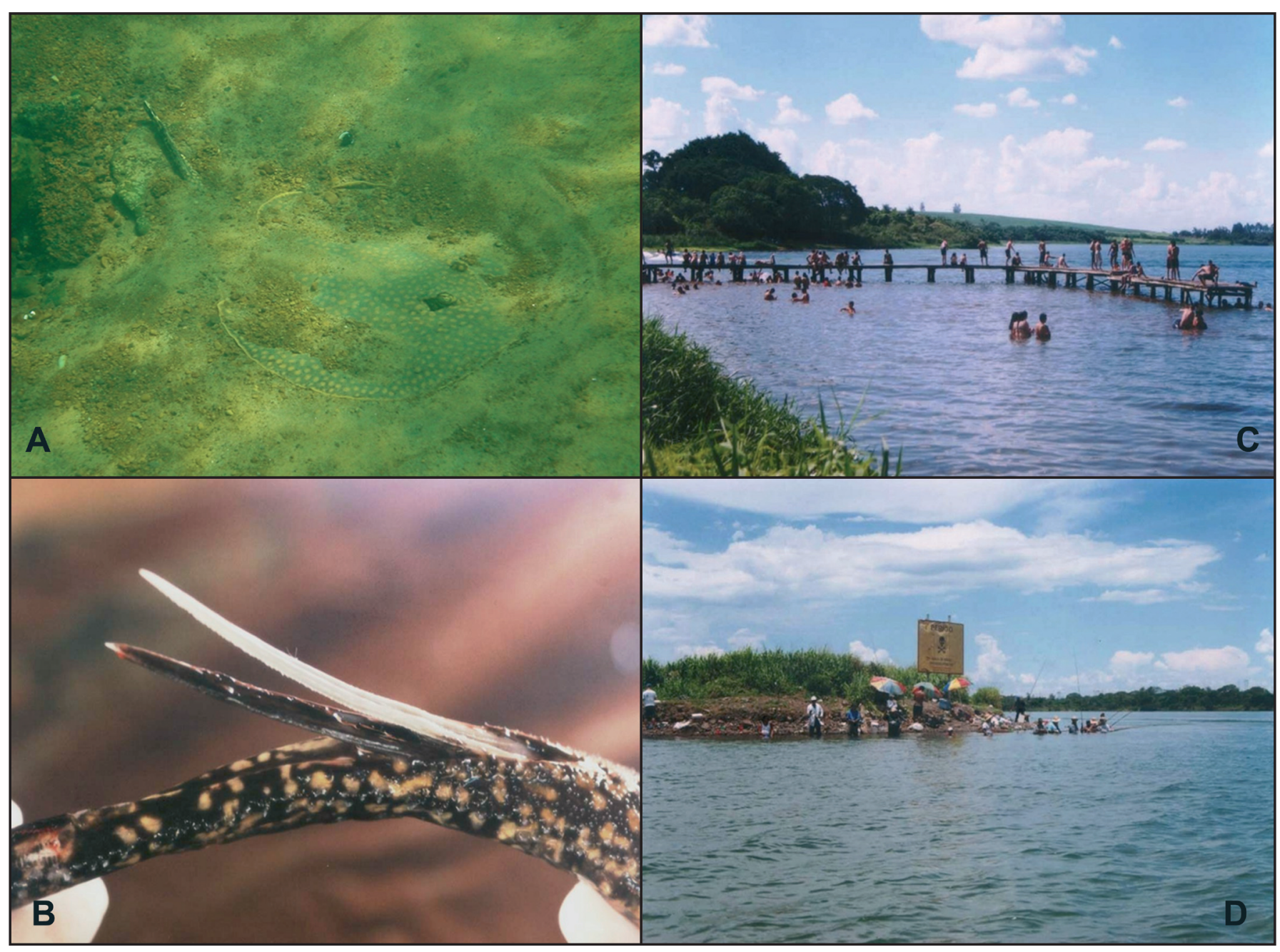

FIGURA 4 - Exemplar de Potamotrygon falkneri em ambiente natural, semi-enterrado na areia, cuja camuflagem dificulta sua visualização e favorece seu pisoteio (A), que normalmente culmina na penetração dos ferrões afiados e retroserrilhados nos membros inferiores das vítimas (B). $O$ banho de rio (C) e a prática da pesca esportiva (D), comuns na região do Alto Rio Paraná, são situações de risco para a ocorrência desse tipo de agravo.

\section{DISCUSSÃO}

Modificações ambientais por obras de engenharia são reconhecidas como importantes facilitadores de invasões biológicas em diversos países ${ }^{13}$. Na região do Alto Rio Paraná, após cerca de 30 anos da submersão das Sete-Quedas, populações de arraias estão se estabelecendo no alto curso do Rio Paraná e nos baixos cursos de tributários importantes, a mais de 350 quilômetros acima do seu ponto inicial de dispersão, constituindo o primeiro caso conhecido de colonização envolvendo espécies de elasmobrânquios em todo o mundo.

No Sudeste do Brasil, acidentes por arraias não faziam parte das ocorrências envolvendo animais peçonhentos e, atualmente, apesar da baixa incidência e total subnotificação, este tipo de agravo já pode ser observado em alguns locais, como na região do Pontal do Paranapanema e da foz do Rio Tietê, na divisa entre os Estados de São Paulo e Mato Grosso do Sul ${ }^{5,7,9}$. Nossos registros demonstraram que tais ocorrências estão acometendo principalmente banhistas e pescadores, de maneira diferente, conforme as atividades desenvolvidas por cada um destes dois grupos.

Banhistas se acidentam durante o dia, notadamente no período vespertino, e apresentam acometimento predominante de membros inferiores, sobretudo tornozelos e pés. Pescadores, tanto profissionais como esportivos, normalmente são atingidos nos membros superiores, especialmente nas mãos, durante o dia ou à noite. No primeiro grupo, o elevado índice de ferimentos nos membros inferiores ocorre por conta das arraias, especialmente os indivíduos juvenis, normalmente permanecerem semi-enterradas na areia ou lodo, próximas às margens, em locais com profundidade inferior a dois metros ${ }^{5}$, o que facilita seu pisoteio. Esse fato é agravado durante o período chuvoso, entre novembro e março, quando a transparência da água reduz drasticamente, dificultando ainda mais a visualização das arraias pelos banhistas e conferindo certa sazonalidade aos acidentes que envolvem este grupo. Entre pescadores, a maior incidência de injúrias nos membros superiores daqueles que praticam a atividade pesqueira embarcados está relacionada à necessidade destes manipularem arraias capturadas acidentalmente em anzóis ou redes, aumentando os riscos de acidentes em função do contato proposital com estes animais. Já os pescadores que executam suas atividades sem o auxílio de embarcações, normalmente utilizando petrechos de pesca como tarrafas ou caniços equipados com iscas artificiais, acidentam-se em condições semelhantes aos banhistas, uma vez que necessitam se deslocar dentro dos rios ou lagoas marginais, com a água na altura da cintura/peito, à procura de locais favoráveis à pesca.

Na região amazônica, acidentes por arraias constituem um importante problema de saúde pública, embora não recebam a 
mesma atenção dispensada para os casos de ofidismo e acidentes envolvendo artrópodes peçonhentos ${ }^{7,14}$. Na região do Alto Rio Paraná, embora o número de ocorrências ainda não seja alarmante, a situação chama a atenção por casos recentes acontecerem em locais situados no extremo norte do ponto inicial de dispersão das arraias na bacia, como Três Lagoas/MS e Castilho/SP, e por estes animais utilizarem os caminhos abertos pelo homem para ampliar sua área de distribuição a cada ano. A observação e a coleta de arraias em Pereira Barreto/SP e Ilha Solteira/SP ilustram essa situação, onde o canal construído para fins hidroviários deve permitir o acesso desses animais às águas do noroeste de São Paulo, além do sudoeste de Minas Gerais e do sul de Goiás. O mesmo deverá ocorrer na região do oeste paulista, onde todas as barragens existentes no Rio Tietê possuem eclusas, o que permitirá sua transposição pelas arraias.

Isso é preocupante pelo fato das arraias não serem nativas da região e estarem colonizando áreas densamente povoadas, onde a população, além de utilizar os rios para diversos fins, muitas vezes desconhece sua presença na bacia e os métodos adequados de prevenção e socorro de acidentes envolvendo esses animais. Se levarmos em conta a existência de inúmeros ranchos e balneários fluviais e a intensa prática da atividade pesqueira na região do Alto Rio Paraná (Figura 4CD), é de se esperar que a interação negativa entre humanos e arraias se intensifique. Com isso, podemos esperar alterações importantes no perfil epidemiológico dos acidentes por animais peçonhentos ocorridos no interior do sudeste brasileiro, com impactos sobre o turismo e sobre a saúde de pescadores profissionais, uma vez que envenenamentos por arraias fluviais apresentam elevada morbidade, com frequentes casos de incapacidade temporária para o trabalho e ulcerações com cicatrização demorada ${ }^{2,7,9,14,15}$.

Como ainda não existe tratamento específico para este tipo de acidente e muitos profissionais de saúde não recebem treinamentos sobre o tema nos cursos de graduação ou no decorrer da atividade profissional, é importante divulgar informações dessa natureza. A literatura e a experiência prática dos autores demonstram que o controle inicial da dor deve ser feito com a imersão imediata do membro atingido em água quente não escaldante (cerca de $60^{\circ} \mathrm{C}$ ), pois as toxinas que provocam dor mostraram-se sensíveis ao calor em experimentos com cobaias $^{7-9,11,14}$ e terem seu efeito vasoconstritor atenuado nas vítimas (V Haddad Jr, D Garrone Neto: dados não publicados). Outros procedimentos incluem a limpeza de ferimentos e procura por fragmentos de ferrões, uso de antibióticos sistêmicos e profilaxia do tétano, infiltração anestésica local e uso de analgésicos sistêmicos, caso a dor não cesse nas primeiras duas horas ${ }^{7}$. A excisão precoce da área comprometida pode ser útil, embora a delimitação da área necrótica nas fases iniciais do quadro seja problemática. As complicações da fase crônica devem ser tratadas com as condutas de cicatrização de úlceras. O uso de corticosteróides sistêmicos é controverso, pois pode aumentar o tempo de cicatrização das úlceras.

Não há, portanto, uma terapia definitiva para os acidentes por arraias, embora seja possível obter o controle do quadro com as medidas propostas. A inativação das toxinas é a única forma ideal de se neutralizar as consequências das ferroadas. No entanto, apesar dos acidentes serem incapacitantes e potencialmente fatais quando infectados, não existe uma justificativa estatística para a produção do soro, devido ao pequeno número reportado de casos. Deve-se ter em mente, porém, que a discussão sobre a produção ou não do soro se torna mais válida quando se observa os sintomas de uma vítima recentemente ferroada por uma arraia e quando os dados obtidos por notificação são praticamente inexistentes.
Dessa forma, a utilização de equipamentos de proteção coletiva, como barreiras físicas, destaca-se como uma importante medida mitigadora no cenário atual que envolve a colonização da região do Alto Rio Paraná por estes animais. Redes ou telas de proteção têm sido utilizadas com sucesso no exterior para evitar o contato de humanos com tubarões e cnidários ${ }^{16,17}$. $\mathrm{Na}$ área de estudo, estamos recomendamos a instalação deste tipo de equipamento em balneários fluviais para reduzir a possibilidade da interação entre banhistas e arraias, em associação com o uso de placas de advertência e com a divulgação de informações junto à população. Como esses animais estão se beneficiando dos caminhos abertos pela Hidrovia Tietê-Paraná para se dispersarem, o monitoramento das arraias deve ser realizado, com o intuito de se acompanhar seus padrões de movimentação e rotas de dispersão na bacia. Ações como alertar as populações situadas nas áreas de risco sobre a presença de arraias, notificar casos de acidentes e capacitar profissionais de saúde para $\mathrm{o}$ atendimento das vítimas, também devem ocorrer, objetivando-se minimizar os impactos dessa colonização.

Vale lembrar que de forma diferente com o que ocorreu com os aparelhos inoculadores de toxinas da grande maioria dos animais peçonhentos, os ferrões das arraias derivam de formas ancestrais que os utilizavam para afugentar predadores e não para a captura de presas. Este fato reforça o conceito de que arraias não são agressivas, utilizando seus ferrões apenas quando pisadas inadvertidamente ou manuseadas sem o devido cuidado.

\section{AGRADECIMENTOS}

Agradecemos a Virgínia S. Uieda, Domingo R. Fernandez, Maria J.A. Vilela, Ricardo S. Rosa, Ottilie C. Forster, Leila M.G. Ribeiro, Sandro G.C. Britto, Mateus F. Feitosa, Kátia C. Barbaro, Marcela S. Lira e aos participantes do estudo, por aceitarem ser entrevistados, fotografados e/ou fornecer informações valiosas utilizadas neste artigo.

\section{CONFLITO DE INTERESSE}

Os autores declaram não haver nenhum tipo de conflito de interesse.

\section{REFERÊNCIAS}

1. Rosa RS. A systematic revision of the South American freshwater stingrays (Potamotrygonida'e) [dissertation]. [Williamsburg]: School of Marine Sciences; 1985 .

2. Castex MN. La Raya Fluvial. Santa Fé: Librería y Editorial Castellví S.A.; 1963.

3. Charvet-Almeida P, Araújo MLG, Rosa RS, Rincon G. Neotropical freshwater stingrays: diversity and conservation status. Shark News 2002; 14:47-51.

4. Vazzoler AEAM, Agostinho AA, Hahn NS. A planície de inundação do Alto Rio Paraná: aspectos físicos, biológicos e sócioeconômicos. Maringá: Editora da Universidade Estadual de Maringá; 1997.

5. Garrone Neto D. História natural, diversidade e distribuição de raias na região do Alto Rio Paraná, Brasil [tese]. [Botucatu]: Universidade Estadual Paulista; 2009

6. Garrone Neto D, Haddad Jr V, Vilela MJA, Uieda VS. Registro de ocorrência de duas espécies de potamotrigonídeos na região do Alto Rio Paraná e algumas considerações sobre sua biologia. Biota Neotrop 2007; 7:1-4. 
7. Garrone Neto D, Haddad Jr V. Acidentes por raias. In: Cardoso JLC, França FOS, Wen FH, Málaque CM, Haddad Jr V, (orgs) Animais peçonhentos no Brasil: biologia, clínica e terapêutica dos acidentes. $2^{\text {a }}$ edição, São Paulo: Editora Sarvier; 2009. p. 295-305.

8. Halstead BW. Poisonous and venomous marine animals of the world. $2^{\text {nd }}$ edition Princeton: The Darwin Press; 1988.

9. Haddad Jr V, Garrone Neto D, Paula Neto JB, Marques FPL, Barbaro KC. Freshwater stingrays: study of epidemiologic, clinic and therapeutic aspects and some enzymatic activies of the venom based on 84 envenomings in humans. Toxicon 2004; 48:287-294.

10. Magalhães MR, Silva Jr NJ, Ulhoa CJ. A hyaluronidase from Potamotrygon motoro (freshwater stingrays) venom: isolation and characterization. Toxicon 2008; 51:1060-1067.

11. Magalhães KW, Lima C, Piran-Soares AA, Marques EE, Hiruma-Lima CA, LopesFerreira M. Biological and biochemical properties of the Brazilian Potamotrygon stingrays: Potamotrygon cf. scobina and Potamotrygon gr. orbignyi. Toxicon 2006; 47:575-583.

12. Barbaro KC, Lira MS, Malta MB, Soares SL, Garrone Neto D, Cardoso JLC, et al. Comparative study on extracts from the tissue covering the stingers of freshwater (Potamotrygon falkneri) and marine (Dasyatis guttata) stingrays. Toxicon 2007; 50:676-687.

13. Vitousek PM, D’Antonio CM, Loope LL, Westbrooks R. Biological invasions as global environmental change. Am Sci 1996; 84:468-478.

14. Pardal PPO. Ictismo por arraia. In: CardosoJLC, França FOS, Wen FH, Málaque CM, Haddad JrV (orgs) Animais peçonhentos do Brasil: biologia, clínica e terapêutica dos acidentes. 2a edIção. São Paulo: Editora Sarvier; 2009. p. 523-529.

15. Garrone Neto D, Cordeiro RC, Haddad Jr V. Acidentes do trabalho em pescadores artesanais do Médio Rio Araguaia, TO, Brasil. Cad Saúde Pública 2005; 21:795803.

16. Cliff G, Dudley FJ. Protection against shark attack in South Africa, 1952-1990. Aust J Mar Freshw Res 1992; 43:263-272.

17. Macrokanis CJ, Hall NL, Mein JK. Irukandji syndrome in northern Western Australia: an emerging health problem. MJA 2004; 181:699-702. 